\title{
Coupling of differential CFD and integral human thermophysiology numerical models applied in indoor ventilated spaces
}

\author{
Eusébio Conceição ${ }^{1 *}$, João Gomes ${ }^{2}$, M. Manuela Lúcio $^{1}$, M. Inês Conceição ${ }^{3}$, André Ramos ${ }^{1}$, and Hazim Awbi ${ }^{4}$ \\ ${ }^{1}$ FCT - Universidade do Algarve, Campus de Gambelas, 8005-139 Faro, Portugal \\ ${ }^{2}$ CINTAL, Campus de Gambelas, 8005-139 Faro, Portugal \\ ${ }^{3}$ Instituto Superior Técnico, Av. Rovisco Pais, 1049-001 Lisboa, Portugal \\ ${ }^{4}$ School of Built Environment, University of Reading, Reading, RG6 6AW, United Kingdom
}

\begin{abstract}
This work presents the development of the coupling of differential Computer Fluid Dynamics and integral human thermo-physiology numerical models applied in indoor ventilated spaces. The study is performed in a virtual chamber, similar to an existing experimental chamber, with dimensions of $4.50 \times 2.55 \times 2.50 \mathrm{~m}^{3}$. The chamber, occupied with twelve virtual manikins, is equipped with six tables, twelve chairs, one exhaust system and one inlet system, based on confluents jets system. In the exhaust system, they are considered six air ducts, located above the head level, connected to the ceiling area. The inlet system, based in four vertical ducts, with $0.15 \mathrm{~m}$ diameter, located on the corners of the chamber, is equipped with consecutive holes, that promotes horizontal jets near the wall. The results demonstrate that when the airflow rate increases the air quality number increases, the thermal comfort number decreases, and the Air Diffusion Index increases slightly. The predicted percentage of dissatisfied index values show that the thermal comfort level of occupants is acceptable, the dioxide carbon concentration values show that the indoor air quality is near the acceptable value and the Draught Risk is acceptable.
\end{abstract}

\section{Introduction}

The confluent jets are defined as a system of multiple jets, in the inlet area, that combine with a single jet, in the outlet area, of the ventilation system. Several studies have been developed on the area of confluent jets ventilation systems. Examples can be seen in Arghand et al. [1], Karimipanah et al. [2], Cho et al. [3], Ghahremanian [4], Yin et al. [5], Ghahremanian and Moshfegh, [6,7], Janbakhsh and Moshfegh [8], and Andersson et al. [9].

To evaluate the thermal discomfort, thermal comfort and indoor air quality levels, different models were developed. These models, inclusively, are published in international standards [10].

Draught Risk (DR) is used to evaluate the local thermal discomfort level that the occupants are subjected. DR was developed by Fanger et al. [11] and depends on temperature, velocity and turbulence intensity of the air. Carbon dioxide $\left(\mathrm{CO}_{2}\right)$ concentration is used to evaluate the indoor air quality level [12]. Predicted Mean Vote (PMV) index and Predicted Percentage of Dissatisfied (PPD) index are used to evaluate the thermal comfort level of the occupants. PMV and PPD indexes, parameters developed by Fanger [13], are applied to determine the thermal comfort conditions in conditioned spaces equipped with Heating, Ventilating and Air Conditioning Systems
[10]. Air Distribution Index (ADI) evaluates simultaneously the air quality level, thermal comfort level, contaminants removal efficiency and heat removal efficiency. ADI was presented and detailed in the studies of Awbi [14], for uniform environments, and Conceição et al. [15], for non-uniform environments. ADI includes the overall performance of a ventilation system.

The software applied in this work simulates the dynamic response of the building, the airflow inside the occupied spaces and the occupants' thermal and thermoregulatory system response. The two last software work in a coupling methodology. The coupling methodology, between Computer Fluid Dynamics (CFD) and Human Thermal Response (HTR) numerical models, can be seen in the studies of Conceição [16], Conceição and Lúcio [17,18], and Conceição et al. $[19,20]$. The software that simulates the Building Dynamic Response (BDR) [21,22] evaluates the air temperature distribution, the surfaces temperature distribution and the energy consumption. Applications of this software are shown in Conceição et al. [23], and Conceição and Lúcio [24,25]. This software considers the evaluation of thermal comfort through the PMV/PPD indexes [26], the adaptive thermal comfort control model [26], and the temperature preferred control model [27].

\footnotetext{
* Corresponding author: econcei@ualg.pt
} 
The main idea of this study is to develop a confluent jets system located in the wall corner, based on vertical ducts with horizontal jets, and an exhausting system, built with six vertical ducts, located above the head level. In the inlet system, the vertical nozzle jets are located near the floor level. In the exhaustion system, the vertical ducts are located along a line at the center of the virtual chamber.

In order to evaluate the ventilation performance, three software, a coupling of the CFD and HTR and a third software that simulate the BDR, and the ADI are used. This study was developed for winter conditions and considers three Cases, each one corresponding to a specific airflow rate.

\section{Models and materials}

This numerical study considers:

- A differential numerical model, that simulates the CFD (Fig. 1). The differential CFD model evaluates the air velocity, air temperature, air turbulence intensity and $\mathrm{CO}_{2}$ concentration [18]. The $\mathrm{CO}_{2}$ concentration, in the respiration area, is used to evaluate the air quality;

- An integral numerical model, HTR (Fig. 2). This integral numerical model simulates the human thermal and thermoregulatory and clothing thermal response, and evaluates the tissue, blood and clothing temperatures distribution [16-20];

- An integral numerical model, BDR. This integral numerical model evaluates the air temperature distribution, surfaces temperature distribution and energy consumption [21-25];

- ADI used to evaluate the ventilation system performance, using the occupant thermal comfort, occupant air quality and ventilation effectiveness for heat and contaminants removal levels [16];

- A DR numerical model, that depends on temperature, velocity and turbulence intensity of the air, used to evaluate the local thermal discomfort level that the people are subjected. In the DR evaluation, the Category $\mathrm{A}$ is associated with $10 \%$, the Category B is associated with $20 \%$ and the Category $\mathrm{C}$ is associated with $30 \%$ [10];

- A thermal comfort numerical model, based on the PMV and PPD indexes, that depends of the air temperature, air relative humidity, Mean Radiant Temperature, air velocity, clothing insulation level and activity level, used to evaluate the thermal comfort level of the occupants, in which Category $\mathrm{C}$ is associated with PPD of $15 \%$ [10].

This numerical study is performed in a virtual chamber, with dimensions of $4.50 \times 2.55 \times 2.50 \mathrm{~m}^{3}$ (see Fig. 1 and Fig. 2):

- Occupied with twelve virtual manikins;

- Equipped with six tables and twelve chairs;

- Equipped with one inlet and one exhaust ventilation systems.

The inlet ventilation system, based on a confluents jets system, is built with four vertical ducts, with 0.125 $\mathrm{m}$ diameter, located on the corners of the chamber, and equipped with consecutive holes, that promotes horizontal jets near the wall. In the present study the consecutive holes are located until $0.25 \mathrm{~m}$ above the floor level. Each duct contains two lines of holes (each line for each adjacent wall surface).

The exhaust ventilation system is constituted by six vertical air ducts, located above the head level. The vertical ducts are located along a line at the center of the ceiling of the virtual chamber.

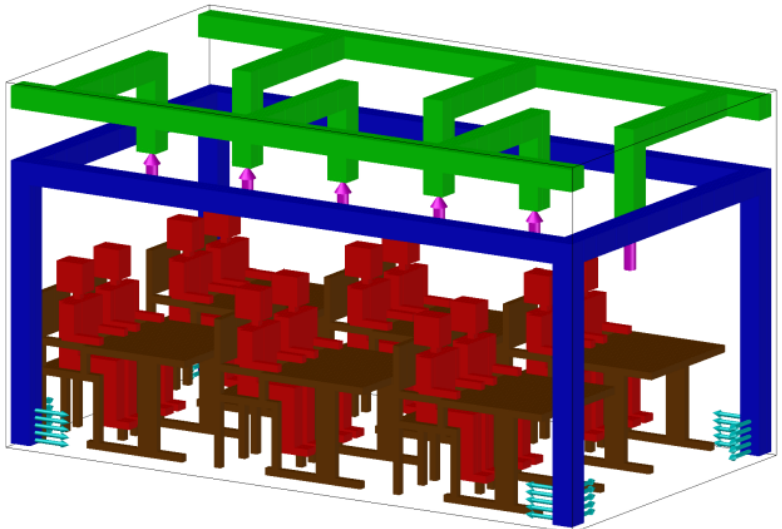

Fig. 1. Scheme of the virtual chamber, equipped with a ventilation system (extraction in green and insufflation in dark blue), the inlet in light blue arrows and outlet in purple arrows, desks (brown) and manikins (red), used in the CFD.

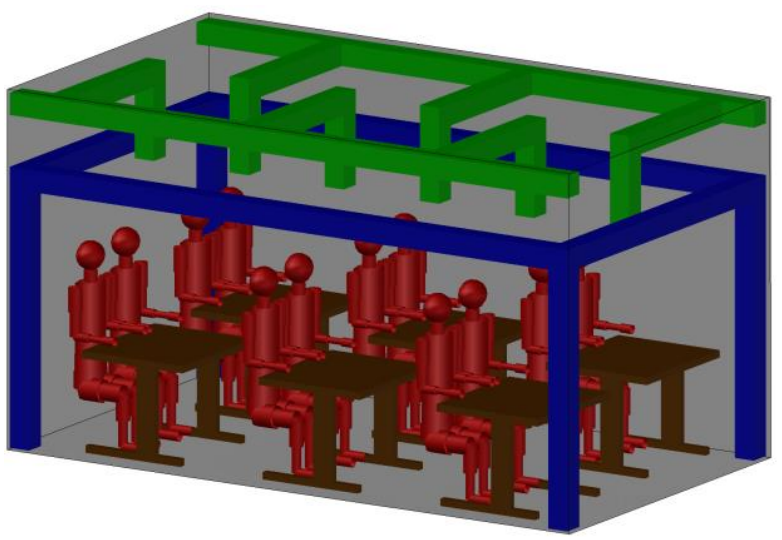

Fig. 2. Scheme of the virtual chamber, equipped with a ventilation system (extraction in green and insufflation in dark blue), desks (brown) and manikins (red), used in the HTC.

The location of the occupants and the number of the occupants is shown in Fig. 3.

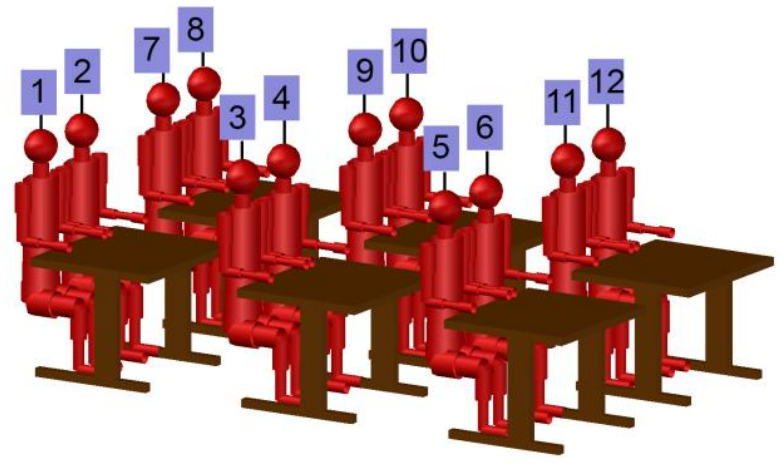

Fig. 3. Location of the occupants and identification of their numbers. 
The numerical simulations were performed for a winter typical day conditions with:

- Indoor mean air temperatures of $20^{\circ} \mathrm{C}$;

- Indoor air relative humidity of $50 \%$;

- Outdoor air temperature of $0^{\circ} \mathrm{C}$.

In the numerical simulation three Cases were studied:

- Case A, defined for an airflow rate for 12 occupants, an inlet air velocity of $0.36 \mathrm{~m} / \mathrm{s}$, an inlet air temperature of $11.6^{\circ} \mathrm{C}$ and a thermal power of $1447.3 \mathrm{~W}$;

- Case B, defined for an airflow rate for 24 occupants, an inlet air velocity of $0.72 \mathrm{~m} / \mathrm{s}$, an inlet air temperature of $15.8^{\circ} \mathrm{C}$ and a thermal power of $3942.6 \mathrm{~W}$;

- Case C, defined for an airflow rate for 36 occupants, an inlet air velocity of $1.08 \mathrm{~m} / \mathrm{s}$, an inlet air temperature of $17.2^{\circ} \mathrm{C}$ and a thermal power of $6438.2 \mathrm{~W}$

It was considered a typical clothing insulation level of 1 clo for winter conditions [10], with a typical level of activity of 1.2 met [10].

\section{Results and discussion}

The air velocity distribution, the air temperature distribution, the DR distribution and the ADI are presented in this section.

\subsection{Environmental variables}

In Fig. 4 to 6, they are presented, respectively, the air velocity distribution, the air temperature distribution and the DR distribution, around the occupants, for winter conditions, for Case A (point a), Case B (point b), and Case C (point c).

The results obtained demonstrate the following:

- When the airflow rate increases, the air velocity around the occupants' sections increases;

- The air velocities around the occupants' sections are higher in the lower members than in the upper members;

- When the airflow rate increases, the air temperature around the occupants' sections decreases slightly;

- The air temperature around the occupants'sections is relatively uniform;

- When the airflow rate increases, the DR around the occupants' sections increases;

- The DR in the Case A is acceptable according to the Category C [10], while in the Case B and in the Case $\mathrm{C}$ the DR is not acceptable mainly in the lower members. However, these sections are protected by clothing.

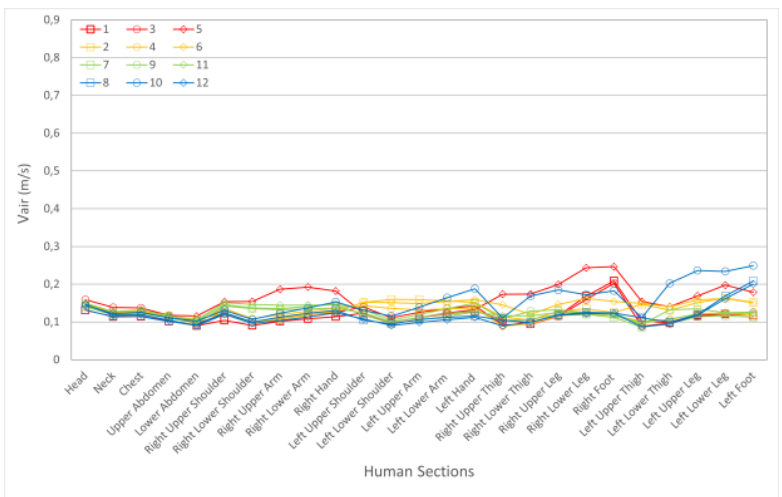

a)

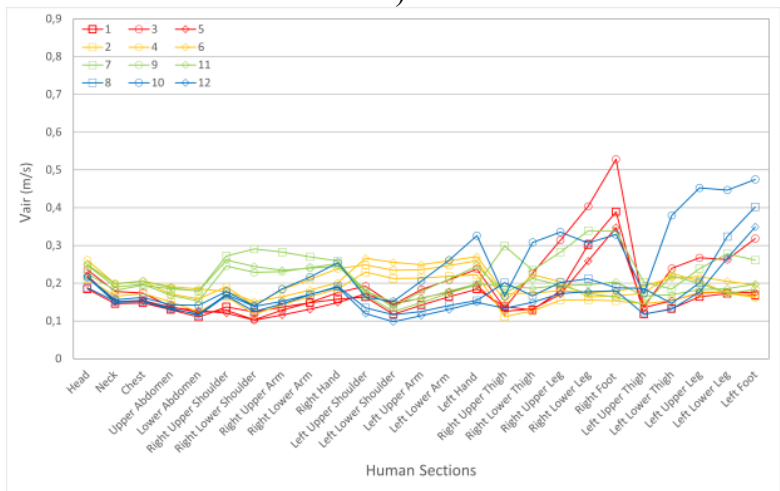

b)

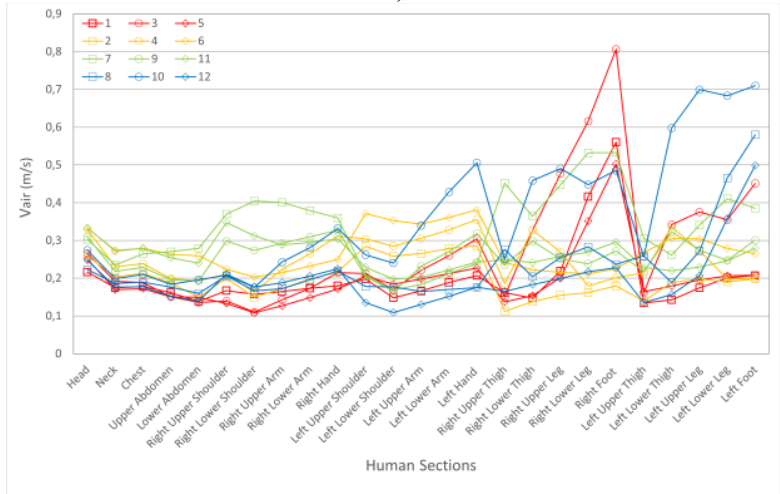

c)

Fig. 4. Air velocity (Vair) distribution around occupants for: a) Case A; b) Case B; c) Case C.

\subsection{Air distribution index}

In Fig. 7, it is presented the PPD and $\mathrm{CO}_{2}$ concentration, that the occupants are subjected, for Case A (point a), Case B (point b), and Case C (point c). The Effectiveness for Heat Removal and Effectiveness for Contaminant Removal, that the occupants are subjected, for Case A (point a), Case B (point b), and Case C (point c), are presented in Fig. 8. In Fig. 9, the ADI, Number of Thermal Comfort and Number of Indoor Air Quality, that the occupants are subjected, for Case A (point a), Case B (point b), and Case C (point c), are presented. 


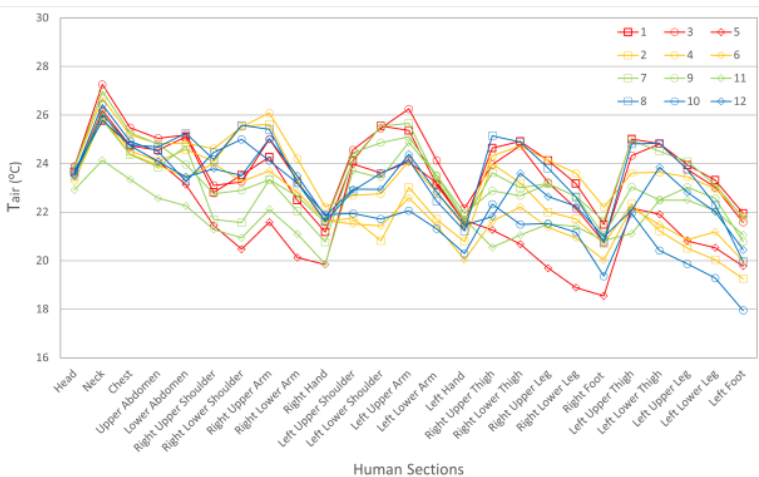

a)

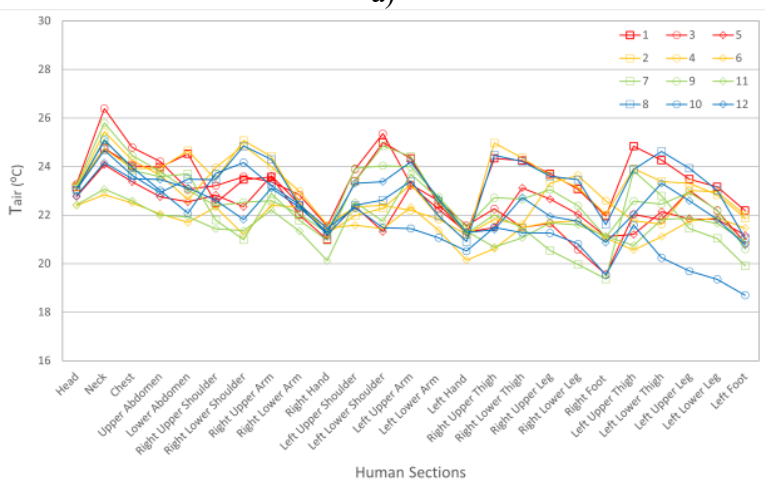

b)

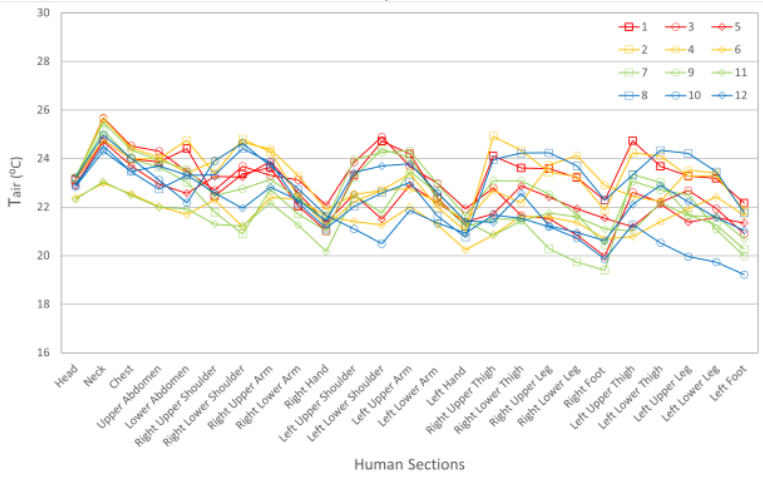

c)

Fig. 5. Air temperature (Tair) distribution around occupants for: a) Case A; b) Case B; c) Case C.

The results obtained demonstrate the following:

- When the airflow rate increases, the $\mathrm{CO}_{2}$ concentration decreases; however, the decrease verified between the Case A and Case B is higher than the decrease verified between the Case $\mathrm{B}$ and Case C;

- In general, the $\mathrm{CO}_{2}$ concentration is according to the acceptable value suggested by the international standards [28];

- In general, the PPD index increases from the Case A to the Case B and decreases from the Case B to the Case C;

- The PPD index is acceptable, according to the Category $\mathrm{C}$ of the international standards [10];

- The effectiveness of heat removal is higher than the effectiveness for contaminant removal;
- When the airflow rate increases, the effectiveness of heat removal decreases;

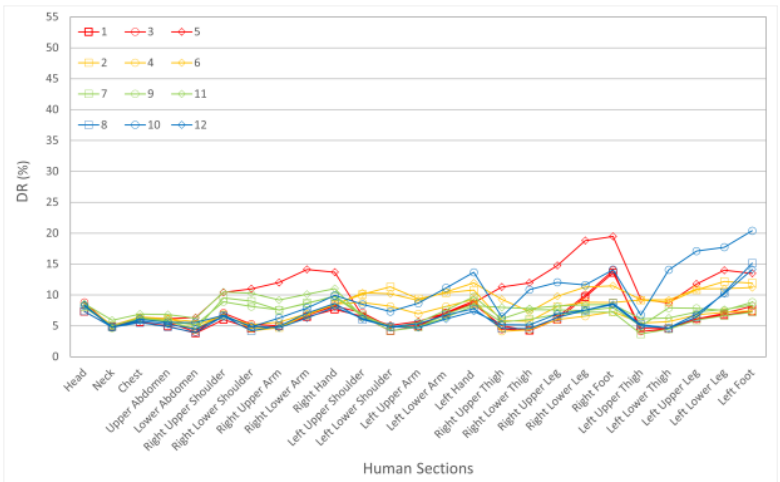

a)

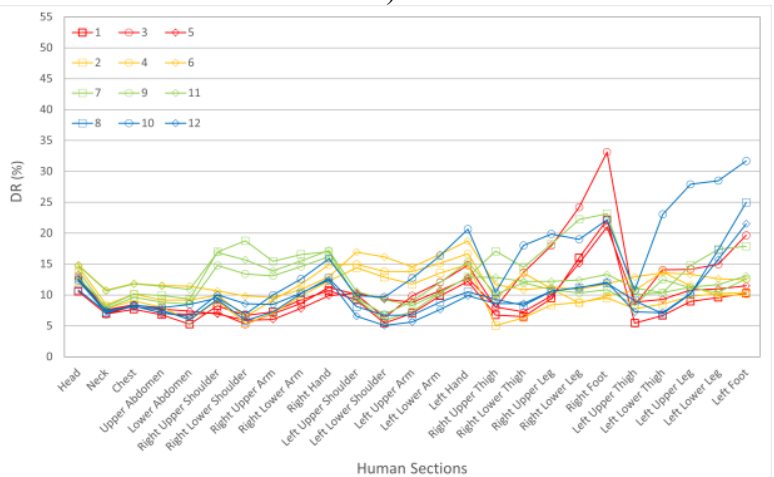

b)

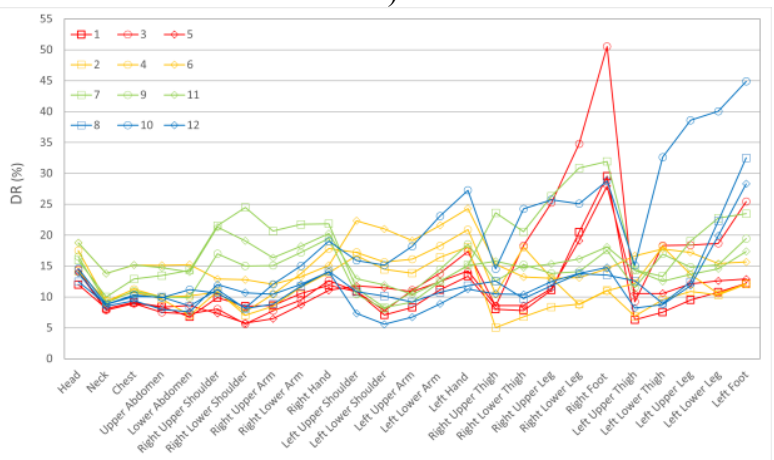

c)

Fig. 6. DR distribution around occupants for: a) Case A; b) Case B; c) Case C.

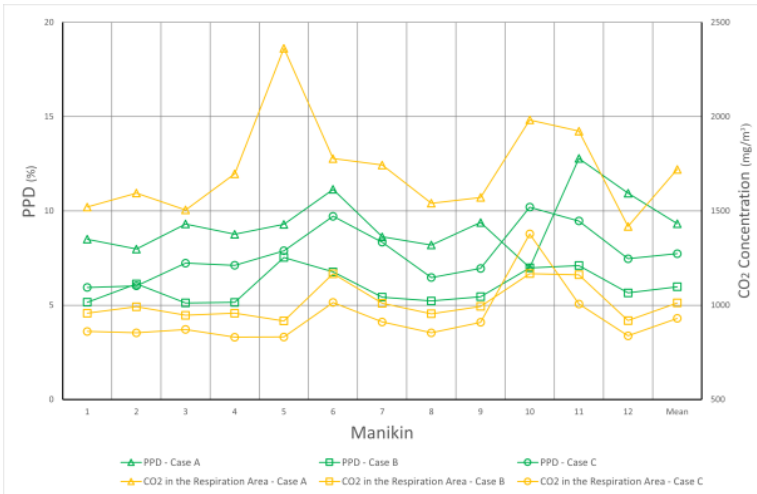

Fig. 7. $\mathrm{PPD}$ and $\mathrm{CO}_{2}$ concentration values that the occupants are subjected for Cases A, B and C. 
- When the airflow rate increases, the effectiveness for contaminant removal is relatively constant;

- When the airflow rate increases, the air quality number decreases;

- The thermal comfort number is highest for the Case $\mathrm{B}$;

- The ADI increases from the Case A to the Case B and is constant between the Case B and the Case C.

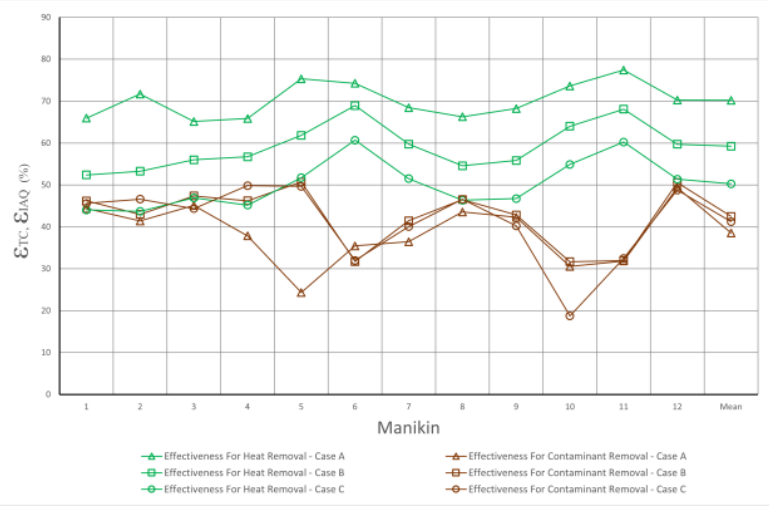

Fig. 8. Effectiveness for Heat Removal and Effectiveness for Contaminant Removal values that the occupants are subjected for Cases A, B and C.

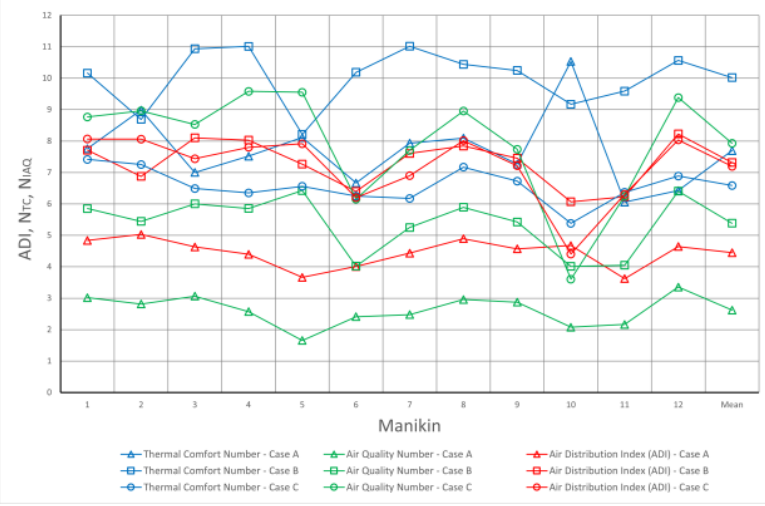

Fig. 9. ADI, Number of Thermal Comfort and Number of Indoor Air Quality values that the occupants are subjected for Cases A, B and C.

\section{Conclusions}

The application of horizontal confluents jets and exhaust systems in a virtual school chamber was made. In the horizontal confluents jets the consecutive holes are located near the floor level, using two lines of holes, each line for each adjacent wall surface. In the exhaust system six vertical ducts are located along a line at the center of the virtual chamber.

The study, developed for winter conditions, considered a virtual chamber occupied with twelve virtual manikins and equipped with six tables and twelve chairs.

When the airflow rate increases, the air velocity and the DR around the occupants' sections increase and the air temperature around the occupants' sections decreases slightly. The air velocities and the DR around the occupants' sections are higher in the lower members than in the upper members. In general, the DR level is acceptable. The lower members present DR uncomfortable levels; however, they are protected by the clothing.

In general, when the airflow rate increases, the $\mathrm{CO}_{2}$ concentration decreases and the concentration values are according to the recommended ones [28].

The PPD index is acceptable, according to the Category C [10], and the lowest PPD index is verified for the case $\mathrm{B}$.

The air quality number decreases when the airflow rate increases and the thermal comfort number is highest for the Case B.

Finally, the highest ADI values are verified for the Cases B and C, while the lowest ADI values are verified for the Case A. Thus, regarding to the results obtained, it is suggested the adoption of Case B, because it promotes acceptable thermal comfort level, air quality level and DR level, with lower airflow rate than the Case C.

The authors would like to acknowledge to the project (SAICTALG/39586/2018) from Algarve Regional Operational Program (CRESC Algarve 2020), under the PORTUGAL 2020 Partnership Agreement, through the European Regional Development Fund (ERDF) and the National Science and Technology Foundation (FCT).

\section{References}

1. T. Arghand, T. Karimipanah, H. Awbi, M. Cehlin, U. Larsson, E. Linden. Build. Environ. 92, 48-60 (2015)

2. T. Karimipanah, H. B. Awbi, C. Blomqvist, M. Sandberg, Effectiveness of confluent jets ventilation system for classrooms, in Proceedings of the $10^{\text {th }}$ International Conference on Indoor Air Quality, 4-9 September 2005, Beijing, China (2005)

3. Y. Cho, H. B. Awbi, T. Karimipanah. Build. Environ. 43, 1091-1100 (2008)

4. S. Ghahremanian, Near-Field Study of Multiple Interacting Jets - Confluent Jets (LiU-Tryck, Linköping, 2014)

5. H. Yin, A. Li, Z. Liu, Y. Sun, T. Chen. Build. Environ. 109, 112-120 (2016)

6. S. Ghahremanian, B. Moshfegh. ASHRAE Trans. 120, 256-270 (2014)

7. S. Ghahremanian, B. Moshfegh. ASHRAE Trans. 120, 271-285 (2014)

8. S. Janbakhsh, B. Moshfegh. Build. Environ. 80, 18-31 (2014)

9. H. Andersson, M. Cehlin, B. Moshfegh. Build. Environ. 137, 18-33 (2018)

10. ISO 7730, Ergonomics of the thermal environment Analytical determination and interpretation of thermal comfort using calculation of the PMV and PPD indices and local thermal comfort criteria (International Organisation for Standardisation, Geneva, 2005) 
11. P. O. Fanger, A. K. Melikov, H. Hanzawa, J. Ring. Energy Build. 12, 21-39 (1988)

12. E. Conceição, M. Lúcio, V. Vicente, V. Rosão. Int. J. Vent. 7, 267-277 (2008)

13. P. Fanger, Thermal comfort (Danish Technical Press, Copenhagen, 1970)

14. Awbi, Ventilation of Buildings (Routledge, 2004)

15. E. Conceição, M. Lúcio, H. Awbi. Build. Simul. 6, 51-67 (2013)

16. E. Conceição, Evaluation of thermal comfort and local discomfort conditions using the numerical modelling of the human and clothing thermal system, in Proceedings of $7^{\text {th }}$ International Conference on Air Distribution in Room, ROOMVENT 2000, 9-12 July 2000, Reading, UK (2000)

17. E. Conceição, M. Lúcio, Numerical and subjective responses of human thermal sensation, in Proceedings of the $6^{\text {th }}$ Portuguese Conference on Biomedical Engineering, 11-12 June 2001, Faro, Portugal (2001)

18. E. Conceição, M. Lúcio. Buildings 6, 38 (2016)

19. E. Conceição, S. Rosa, A. Custódio, R. Andrade, M. Meira, M. Lúcio. HVACR Res. 16, 401-412 (2010)

20. E. Conceição, M. Lúcio, J. Farinho, Experimental and numerical study of personalized of ventilation in classrooms desks, in Proceedings of the 10th International Conference in Rooms, RoomVent, 13-15 June 2007, Helsinki, Finland (2007)

21. E. Conceição, M. Silva, J. André, D. Viegas. Int. J. Veh. Des. 24, 372-387 (2000)

22. E. Conceição, M. Lúcio. Build. Simul. 3, 245-261 (2010)

23. E. Conceição, M. Lúcio, M. Lopes. WSEAS Trans. Environ. Dev. 4, 644-654 (2008)

24. E. Conceição, M. Lúcio. Indoor Built Environ. 19, 657-667 (2010)

25. E. Conceição, M. Lúcio. Indoor Built Environ. 18, 41-51 (2009)

26. Conceição, J. Gomes, A. Ruano. IFAC PapersOnLine 51, 20-25 (2018)

27. E. Conceição, M. Lúcio, A. Ruano, E. Crispim. Build. Environ. 44, 871-877 (2009)

28. ANSI/ASHRAE-62.1 Standard, Ventilation for Acceptable Indoor Air Quality (ASHRAE, Atlanta, 2016) 